\title{
Levantamento de pesquisas sobre cultura escolar no Brasil*
}

Adriane Knoblauch

Ana Lúcia Silva Ratto

Luciane Paiva Alves de Oliveira

Valéria Milena Rohrich Ferreira

Universidade Federal do Paraná

Correspondência:

Adriane Knoblauch

adrianeknoblauch@gmail.com

* Este artigo é uma versão

ampliada de uma comunicação apresentada na $34^{\mathrm{a}}$ Reunião Anual da ANPEd, em outubro de 2011, no

GT sobre educação fundamental.

\section{Resumo}

A presente pesquisa procurou examinar o modo como a noção de cultura escolar vem sendo apropriada pelas pesquisas que tomam a escola brasileira como objeto de estudo, especialmente no que se refere às investigações sobre o ensino fundamental. Para isso, realizou-se um levantamento da produção discente dos programas de pós-graduação stricto sensu entre os anos de 1987 e 2007, conforme registro do Banco de Teses da Capes. Por meio desse balanço, foram selecionados 361 resumos de dissertações e teses que faziam referência ao termo cultura escolar. Em seguida, procedeu-se à elaboração de um instrumento que permitiu o exame de variáveis que puderam expressar as características de tal produção. A análise desses vinte anos de produção indica uma tendência de aumento dos estudos sobre cultura escolar ao longo dos anos, bem como uma concentração dessas pesquisas no eixo Sul-Sudeste do país. Além disso, foi constatada dispersão na orientação das pesquisas, havendo algum esforço de concentração apenas em poucos programas ou em alguns orientadores. Outra constatação refere-se à alta representatividade dos estudos relativos ao ensino fundamental, sobretudo aqueles que tratam de formação de professores, organização escolar por meio de ciclos, gestão escolar, política educacional, currículo e metodologias de ensino. Por fım, é possível concluir que a noção de cultura escolar tem sido significativa para a compreensão do ensino fundamental.

\section{Palavras-chave}

Ensino fundamental - Cultura escolar - Teses e dissertações. 


\section{Survey of research on school culture in Brazil*}

Adriane Knoblauch

Ana Lúcia Silva Ratto

Luciane Paiva Alves de Oliveira

Valéria Milena Rohrich Ferreira

Universidade Federal do Paraná

Contact:

Adriane Knoblauch

adrianeknoblauch@gmail.com

* This paper is an expanded version of a presentation delivered in the 34th Annual Meeting of ANPEd (the National Association of Educational Research), in October 2011, at the Work Group on elementary/intermediate education.

\section{Abstract}

This research attempted to examine the way the notion of school culture has been appropriated by investigations that take the Brazilian schools as their object of study, especially those concerning research on elementary and intermediate schooling. It started with a survey of the students' production in graduate programs between 1987 and 2007, as found in the Theses Bank of Capes. After that, 361 abstracts from dissertations and theses were selected as they referred the term school culture. Next, an instrument was developed to examine the variables that could express the characteristics of such production. The analysis of twenty years of academic production indicates a tendency that studies on school culture has been on the rise along the years, as well as a concentration of such investigations in the South-Southeast axis of Brazil. In addition, dispersion was found in the supervision of researches, as there some effort of concentration just in a few programs or a few supervisors. Another finding concerns the high representativeness of studies related to elementary and intermediate schooling, mainly those dealing with teacher education and training, school organization by means of cycles, school management, educational policy, curriculum and teaching methodologies. Finally, one may conclude that the notion of school culture has been meaningful to understand the elementary and intermediate schooling.

\section{Keywords}

Elementary and intermediate schooling - School culture - Theses and dissertations. 
No âmbito das ciências sociais, o interesse pelos aspectos que forjam o interior da escola muitas vezes é atribuído ao que denominamos Nova Sociologia da Educação (NSE), um movimento que teve seu marco na Inglaterra a partir da publicação, em 1971, do livro Knowledge and control, organizado por Michel Young. Tal iniciativa deu-se na medida em que a NSE criticou os estudos vinculados à aritmética política, tendência majoritária naquele país que consistia na realização de grandes levantamentos estatísticos sobre o sistema de ensino, desconsiderando os elementos que compõem o dia a dia escolar e seus impactos no processo educacional (SILVA, 1999). Nessa empreitada, novos temas e conceitos foram incorporados às investigações, as quais deveriam entender a escola sob um olhar menos naturalizado. Essas pesquisas, que tiveram início na década de 1960 , sobretudo na Europa, viriam a constituir a NSE.

Entretanto, um trabalho que pode ser considerado precursor desse interesse pelo interior da escola é o de Willard Waller (1961). Seu estudo, já na década de 1930, propunha a ideia de que a escola tem uma cultura que se diferencia da de outras instituições, tendo em vista seus valores e seu sistema simbólico. Ainda que sua análise não tenha ocorrido de forma crítica, sua originalidade merece ser destacada.

Já no Brasil, desde os anos 1950, Antônio Cândido advertia para uma dinâmica própria da escola, a qual seria resultado da integração entre seus membros e a relação mantida com a estrutura social externa. A esse respeito, ele destacava que, apesar de a organização administrativa ser semelhante a todas as escolas, cada instituição apresenta características únicas por desenvolver de maneira singular suas sociabilidades. Para o autor, as pesquisas sociológicas poderiam ser profícuas no âmbito educacional justamente na medida em que ajudassem a desvelar os elementos dessa diferenciação da estrutura interna da escola (CÂNDIDO, 1979).

Atualmente, uma nova perspectiva de análise vem-se destacando nos estudos que procuram compreender a dinâmica interna da escola, ou seja, aquela que trabalha com a ideia de cultura escolar. Segundo Vidal (2005), tal perspectiva ganhou impulso no Brasil a partir da publicação de textos de Jean Hébrard e André Chervel, na revista Teoria e Educação de 1990, seguidos do artigo de Jean-Claude Forquin, em 1992. Os dois primeiros problematizam elementos importantes para a história das disciplinas escolares e o terceiro reflete sobre a maneira como a sociedade e a escola selecionam aspectos culturais para a transmissão de conhecimentos.

Outra referência importante é o artigo Cultura escolar brasileira: um programa de pesquisa, publicado por José Mário Pires Azanha (1990-1991), o qual propunha o mapeamento cultural da escola como eixo norteador de um amplo trabalho investigativo a ser realizado de maneira integrada pelos docentes da Faculdade de Educação da Universidade de São Paulo. Tal programa se configuraria como uma linha de pesquisa cujo intuito seria compreender o que é a escola, uma vez que, segundo o autor, suas complexas relações seriam praticamente desconhecidas pelos estudiosos da área. De acordo com Azanha (1990-1991):

Não se trata, simplesmente, de caracterizar os protagonistas que atuam no espaço escolar e relacioná-los a condições sociais, políticas e econômicas, procedimento que poderia sugerir relações de causa e efeito que, muitas vezes, implicam pressupostos obscuros e simplistas. 0 que interessa é descrever as "práticas escolares" e os seus correlatos (objetivados em mentalidades, conflitos, discursos, procedimentos, hábitos, atitudes, regulamentações, "resultados escolares" etc.). Somente o acúmulo sistemático dessas descrições permitirá compor um quadro compreensivo da situação escolar, ponto de partida para um esforço de explicação e de reformulação. (p. 38)

Naquele momento, Azanha sugere que o saldo das pesquisas educacionais é insuficiente 
para ajudar a compreender o que é a escola e indica que, muitas vezes, isso nos fez entendê-la de forma superficial.

Essa intensificação de esforços investigativos a respeito da cultura escolar - ou culturas escolares, conforme assinala Viñao Frago (2001) - faz com que novos assuntos passem a ser discutidos, contando com contribuições de diversos campos do conhecimento, no intuito de entender as práticas desenvolvidas no interior das escolas e os desdobramentos disso em relação à sociedade. Para tanto, foi necessário ampliar as fontes, os referenciais e os métodos tradicionalmente utilizados, procurando contemplar aspectos até então ignorados.

Se, por um lado, esse investimento é fundamental para desvendar aquilo que nessa tradição convencionou-se chamar de caixa preta da escola, por outro, ele colabora para que desmitifiquemos os discursos abstratos e genéricos que relegam a instituição escolar a um estado de sucumbência e impotência mediante as pressões sociais.

Esse panorama também determinou uma mudança significativa nos parâmetros do próprio sentido dado à cultura localizada na escola, a qual deixou de ser tida como reflexo do mundo social e passou a ser compreendida como um espaço complexo, composto por um conjunto de interseções que colaboram para instituir uma identidade impar, extremamente dinâmica e inventiva do ponto de vista cultural. Nos dizeres de Chervel (1990):

porque o sistema escolar é detentor de um poder criativo insuficientemente valorizado até aqui é que ele desempenha na sociedade um papel que não se percebeu que era duplo: de fato ele forma não somente os indivíduos, mas também uma cultura que vem por sua vez penetrar, moldar, modificar a cultura da sociedade global. (p. 184)

Ao examinar A cultura escolar como categoria de análise e como campo de investigação na história da educação brasileira, Faria Filho et al. (2004) apontam valiosas contribuições sobre a circulação, o uso e a apropriação do termo cultura escolar no Brasil. Eles destacam três grandes eixos norteadores entre as pesquisas já realizadas: 1) saberes, conhecimentos e currículos; 2) espaços, tempos e instituições escolares; 3) materialidade escolar e métodos de ensino.

Ainda nessa perspectiva, Faria Filho et al. (2004) indicam Julia, Chervel, Forquin e Viñao Frago como autores que apresentam importantes reflexões a respeito da cultura escolar. Assim, mencionam que, mesmo localizando diferenças conceituais decorrentes dos diversos objetos de investigação desses autores, também existem proximidades que oferecem um repertório analítico a partir do qual é possível compreender as estruturas invariantes da escola. Concomitantemente, chamam atenção para o fato de que essas semelhanças e diferenças também devem servir de alerta "à sua incorporação nos estudos no Brasil, pela atenção às diversidades culturais, sociais e históricas da escolarização entre os diferentes países” (p. 149).

A título de ilustração, é possível afırmar que Dominique Julia (2001) indica a cultura escolar em uma perspectiva abrangente, englobando

um conjunto de normas que definem conhecimentos a ensinar e condutas a inculcar, e um conjunto de práticas que permitem a transmissão desses conhecimentos e a incorporação desses comportamentos; normas e práticas coordenadas a finalidades que podem variar segundo as épocas. (p. 10)

Viñao Frago (1995) aponta a cultura escolar de forma muito próxima à definição oferecida por Julia. Segundo ele, cultura escolar pode ser entendida como:

conjunto de aspectos institucionalizados - incluye prácticas y conductas, modos de vida, hábitos y ritos - la historia cotidiana del hacer escolar -, objetos materiales - función, uso, distribución en el espacio, 
materialidad física, simbología, introducción, transformación, desaparición... -, y modos de pensar, así como significados e ideas compartidas. (p. 68-69)

Forquin (1993), por sua vez, ao discutir sobre as bases do conhecimento escolar a partir da sociologia e da antropologia, diferencia cultura escolar e cultura da escola:

A escola é também um "mundo social", que tem suas características de vida próprias, seus ritmos e seus ritos, sua linguagem, seu imaginário, seus modos próprios de regulação e de transgressão, seu regime próprio de produção e de gestão de símbolos. E esta "cultura da escola" (no sentido em que se pode também falar da "cultura da oficina" ou da "cultura da prisão") não deve ser confundida tampouco com o que se entende por "cultura escolar", que se pode definir como o conjunto dos conteúdos cognitivos e simbólicos que, selecionados, organizados, "normalizados", "rotinizados", sob o efeito dos imperativos de didatização, constituem habitualmente o objeto de uma transmissão deliberada no contexto das escolas. (p. 167)

Já do ponto de vista das ciências sociais, Pérez Gómez (2001) considera a escola como um espaço de cruzamento de culturas, pois, em seu interior, convivem diferentes propostas, ou seja, a cultura crítica (produção cultural acumulada ao longo da história humana), a cultura acadêmica localizada no currículo, a cultura social (valores hegemônicos), a cultura institucional da escola (normas, rituais, rotinas) e ainda a cultura da experiência do aluno, adquirida em sua vida diária.

Para Silva (2006), da história à sociologia, são várias as abordagens que têm tomado a escola como objeto de estudo em nosso país. Mas, independentemente da abordagem, um elemento faz-se presente em qualquer análise, a saber: o reconhecimento da existência de uma cultura própria dessa instituição. Cultura que a conforma de maneira muito particular, com uma prática social própria e única. (p. 201-202)

No que se refere aos interesses da presente pesquisa, ao compartilhar dos pressupostos que compõem essa tradição investigativa, também foi forçoso reconhecer a necessidade de entender melhor os impactos dela sobre os estudos brasileiros. Assim, realizamos um levantamento sobre a produção discente dos programas de pós-graduação stricto sensu no Brasil, com o intuito de mapear o modo como a temática da cultura escolar aparece nesse cenário em âmbito nacional. Para tanto, selecionamos os resumos das dissertações e teses registradas no Banco de Teses da Capes (Coordenação de Aperfeiçoamento de Pessoal Docente do Ensino Superior) entre os anos de 1987 a 2007, a partir da noção de cultura escolar.

Estamos cientes de que o conjunto das produções teóricas em torno da perspectiva da cultura escolar não se resume ao que consta nesse banco de dados, bem como do fato de que esse balanço não esgota as possibilidades investigativas em torno da produção brasileira sobre o assunto. Além disso, é importante frisar que nossa aproximação com tal universo deu-se a partir da leitura dos resumos desses trabalhos e, portanto, está inevitavelmente sujeita ao caráter sintético desse tipo de texto e às variações nos modos de construí-lo. Também pode haver pesquisas que se aproximaram da perspectiva dos estudos de cultura escolar, mas que, por não mencionarem o termo no resumo, não serão aqui analisadas.

Apesar de tais circunstâncias, esses pontos não invalidam a importância do tipo de aproximação que aqui realizamos, uma vez que o acervo pesquisado proporcionou interpretações relevantes, além de novos questionamentos, conforme veremos na sequência do artigo.

Primeiramente, acionamos o banco de teses a partir do termo cultura escolar no campo 
expressão exata, o que resultou em um total de 409 resumos. Como o sistema de busca captou resumos com a expressão exata, mas também aproximada, optamos por manter aqueles que indicavam, além do termo cultura escolar, os termos cultura(s) da escola e cultura(s) na escola, o que nos levou a fazer novas buscas no banco de teses com essas últimas expressões; no entanto, os resumos apresentados pelo sistema foram os mesmos. Por outro lado, foram descartados 48 trabalhos, pois, mesmo captados a partir de palavras próximas ao termo cultura escolar, uma leitura criteriosa e integral dos resumos demonstrou que não se relacionavam com o nosso interesse. Por fim, chegamos ao conjunto de 361 resumos $^{1}$.

No intuito de organizar os dados, construímos um banco de registros com os principais elementos caracterizadores dessa produção. Para isso, selecionamos um conjunto de variáveis ${ }^{2}$, sendo que algumas emergiram das informações imediatamente reveladas pelo formulário da Capes e outras se estabeleceram a partir das primeiras leituras dos resumos, ou seja, na medida em que se mostraram promissoras para a investigação. A partir do escrutínio desses dados, conseguimos contemplar quase a totalidade das informações oferecidas pelos resumos. 0 resultado de tal levantamento constitui a base de nossas interpretações, as quais discutiremos a seguir.

\section{Características das teses e dissertações sobre cultura escolar}

No texto intitulado A sociologia dos estabelecimentos escolares: passado e presente de um campo de pesquisa em re-construção, Mafra (2003) tece considerações sobre a diferenciação entre cultura escolar, cultura da escola e cultura na escola. Para ela, a cultura na escola se voltaria particularmente para as questões rela-

1- Vale destacar que, em 2008, ano em que procedemos à busca, o Banco de Teses da Capes continha resumos de trabalhos defendidos até 2007. 2- As variáveis foram as seguintes: autor/a; título; ano; grau; programa; orientador; banca; palavras-chave; área de conhecimento; temáticas; termo utilizado; problema/objetivos; metodologia/fontes; local/período pesquisado; nível/modalidade; autores citados/conceitos; conclusões. tivas aos diferentes grupos culturais existentes no espaço escolar, suas marcas identitárias e os modos como interagem entre si e com a cultura hegemônica no cotidiano. Já os trabalhos que utilizam a noção cultura da escola referem-se às investigações sobre a identidade da escola, seu ethos cultural, as marcas que a definem como instituição (suas normas/burocracias, linguagens; suas relações com tempo, espaço, poder; as interações entre seus sujeitos; suas representações e resistências), tal como apontado por Forquin (1993). Por fim, a autora identifica as pesquisas voltadas para a cultura escolar associando-as aos estudos que se dirigem à busca do ethos escolar, mais necessariamente a partir de um enfoque histórico.

Assim, um dos primeiros propósitos da pesquisa foi identificar o percentual de trabalhos que apresentavam as expressões cultura escolar, cultura da escola, cultura na escola e culturas - da escola, na escola e escolar, tentando avaliar se essa diferenciação se tornaria significativa para a investigação.

A partir da organização dos dados, chegamos ao seguinte agrupamento:

Tabela 1 - Termo utilizado nas teses e dissertações

\begin{tabular}{l|c:c}
\hline Termo & Frequência & Percentual \\
\hline Cultura da escola & 23 & $6,37 \%$ \\
\hline Cultura escolar & 313 & $86,70 \%$ \\
\hline Cultura na escola & 04 & $1,11 \%$ \\
\hline Culturas-daescola,naescolaeescolar & 21 & $5,82 \%$ \\
\hline Total & \multirow{2}{*}{361} & $100 \%$ \\
\hline
\end{tabular}

Fonte: Banco de Teses da Capes (1987/2007).

A respeito do uso de termos (cultura da escola, cultura escolar, cultura na escola ou, ainda, culturas - da escola, na escola e escolar), foi possível verificar que $86,70 \%$ da produção (ou seja, 313 trabalhos) utiliza o termo cultura escolar. Isso demonstra a ascendência desse termo sobre os demais, que juntos não chegam aos 14\%. 
No entanto, o exame dos dados coletados no banco de teses evidencia que muitos pesquisadores utilizam esses termos de formas variadas, o que pode indicar uma prática investigativa que não visualiza a necessidade e/ ou a importância de classificações como aquelas apontadas por Mafra (2003). Dentre essa variedade de usos, o que pode ser aferido é a primazia do emprego do termo cultura escolar, o qual, para além das pesquisas históricas, é também frequente entre as pesquisas contemporâneas que buscam compreender a dinâmica escolar.

Isso parece corroborar a análise de Silva (2006), que afirma:

Seja cultura escolar ou cultura da escola, esses conceitos acabam evidenciando praticamente a mesma coisa, isto é, a escola é uma instituição da sociedade, que possui suas próprias formas de ação e de razão, construídas no decorrer da sua história, tomando por base os confrontos e conflitos oriundos do choque entre as determinações externas a ela e as suas tradições. (p. 206)

Nesse âmbito, outro aspecto que se mostrou expressivo a partir da tabulação dos dados foi o delineamento de pelo menos duas grandes concentrações entre os tipos de pesquisa: uma relacionada aos estudos históricos e outra a pesquisas que estudavam a escola do ponto de vista da atualidade/contemporaneidade. Houve apenas três trabalhos em que não se pôde identificar de que campos se tratavam, tendo em vista a insuficiência das informações presentes nos resumos. Assim, recorremos a uma opção metodológica e passamos a organizar os dados com a seguinte delimitação: estudos históricos para trabalhos voltados às temáticas da história da educação e estudos contemporâneos para pesquisas que analisam as manifestações recentes sobre/da escola (considerando o momento em que o estudo foi realizado). Segue um balanço dessas concentrações:
Tabela 2 - Teses e dissertações de acordo com o tipo de estudo (contemporâneo ou histórico)

\begin{tabular}{|c|c|c|}
\hline Tipo de estudo & Frequência & Percentual \\
\hline Contemporâneos & 245 & $67,87 \%$ \\
\hline Históricos & 113 & $31,30 \%$ \\
\hline Indefinidos & 3 & $0,83 \%$ \\
\hline Total & 361 & $100 \%$ \\
\hline
\end{tabular}

Fonte: Banco de Teses da Capes (1987/2007).

Na tabela 2, verificamos que os números indicam um percentual maior de trabalhos contemporâneos: mais de $2 / 3$ do total. No entanto, quando consideramos que, no agrupamento do tipo contemporâneo, foram reunidos estudos de diferentes vertentes (antropologia, sociologia, psicologia etc.), fato que não se repetiu com aqueles do tipo histórico, temos necessariamente que salientar a expressiva produção de pesquisas históricas sobre o assunto, o que indica sua alta representatividade no universo investigado.

Em relação à representatividade, outro ponto que merece destaque é a incidência do termo cultura escolar nos trabalhos produzidos entre 1987 e 2007. Nesse balanço podemos verificar que a primeira pesquisa surge em 1993, com uma elevação relativa a partir de 1995.

Tabela 3-Quantidade de teses e dissertações sobre cultura escolar

\begin{tabular}{|c|c|c|}
\hline Ano & Frequência & Percentual \\
\hline 1987 a 1992 & 0 & $0 \%$ \\
\hline 1993 & 1 & $0,28 \%$ \\
\hline 1994 & 0 & $0 \%$ \\
\hline 1995 & 2 & $0,56 \%$ \\
\hline 1996 & 5 & $1,38 \%$ \\
\hline 1997 & 6 & $1,66 \%$ \\
\hline 1998 & 4 & $1,11 \%$ \\
\hline 1999 & 5 & $1,38 \%$ \\
\hline 2000 & 11 & $3,05 \%$ \\
\hline 2001 & 19 & $5,26 \%$ \\
\hline 2002 & 27 & $7,48 \%$ \\
\hline 2003 & 35 & $9,7 \%$ \\
\hline 2004 & 65 & $18 \%$ \\
\hline 2005 & 49 & $13,57 \%$ \\
\hline 2006 & 61 & $16,90 \%$ \\
\hline 2007 & 71 & $19,67 \%$ \\
\hline Total & 361 & $100 \%$ \\
\hline
\end{tabular}

Fonte: Banco de Teses da Capes (1987/2007). 
Apesar de o primeiro trabalho ser localizado em 1993, é a partir de 1996 que o crescimento se efetiva, apresentando um pico no ano de 2004, uma ligeira queda em 2005 e uma retomada progressiva nos anos subsequentes, conforme representado no gráfico a seguir.

Gráfico 1 - Ascensão na produção de teses e dissertações sobre cultura escolar

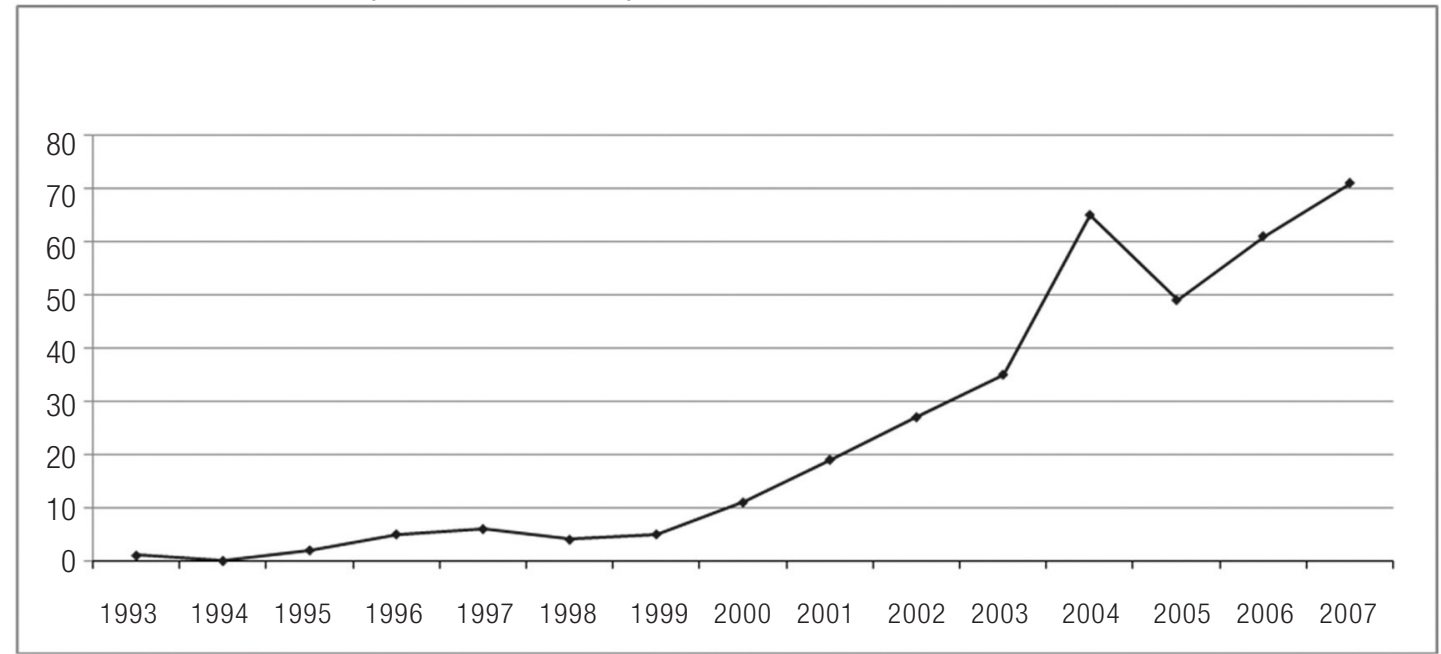

Fonte: Banco de Teses da Capes (1987/2007).

É possivel que a proposição investigativa sugerida por Azanha (1990-1991) tenha impulsionado essa produção, efetivando-se na USP, mas também se irradiado em outros programas brasileiros de pós-graduação. Vale lembrar que, naquele momento, o autor ressalta a importância de conhecermos a escola a partir de um

amplo conjunto de investigações (multi e interdisciplinares) capazes de cobrir o amplo espectro das manifestações culturais que ocorrem no ambiente escolar. (p. 39)

Também é legítimo afirmar que o crescimento na produção de pesquisas tem estreita relação com a inserção da noção de cultura escolar no Brasil, sobretudo pela leitura dos autores europeus que vêm dedicando-se a ela, conforme afirmam Silva (2006), Faria Filho et al. (2004), e Souza e Faria Filho (2006).

Ainda no que se refere à quantificação desses estudos, outro cruzamento importante é a distribuição dessas pesquisas entre teses e dissertações, ou seja, pelo grau de titulação obtido pelos autores. Examinemos:
Tabela 4 - Distribuição dos estudos pelo grau de titulação

\begin{tabular}{l|c:c}
\hline Grau & Frequência & Percentual \\
\hline Doutorado & 85 & $23,54 \%$ \\
\hline Mestrado & 275 & $76,18 \%$ \\
\hline Profissionalizante & 1 & $0,28 \%$ \\
\hline Total & 361 & $100 \%$ \\
\hline
\end{tabular}

Fonte: Banco de Teses da Capes (1987/2007).

Analisando os dados da tabela, é possível observar que a maior parte da produção refere-se às dissertações de mestrado, que representam mais de 3/4 do total. Em segundo lugar, como era de se esperar, aparecem teses de doutorado, com 23,54\%, seguidas de apenas um mestrado profissionalizante. Essa distribuição acompanha a produção da pós-graduação brasileira de um modo geral, que, de acordo com dados fornecidos pela Capes, entre 1998 e 2007 foi representada por $77,03 \%$ de dissertações e 22,96\% de teses ${ }^{3}$.

Dentre os programas de pós-graduação no Brasil que desenvolveram teses e dissertações en-

3 - Conforme <http://geocapes.capes.gov.br/geocapesds/>. Acesso em: 15 dez. 2010. 
volvendo a temática, foram localizados 84 , dos quais os quinze com maior representatividade estão a seguir relacionados:

Tabela 5 - Programas de pós-graduação e quantidade de teses e dissertações

\begin{tabular}{|c|c|c|c|}
\hline & $\begin{array}{l}\text { Programas de pós- } \\
\text { graduação }\end{array}$ & Frequência & Percentual $^{4}$ \\
\hline 01 & $\begin{array}{l}\text { PUC/SP - Educação: História, } \\
\text { Política, Sociedade }\end{array}$ & 41 & $11,35 \%$ \\
\hline 02 & USP - Educação & 37 & $10,24 \%$ \\
\hline 03 & UFPR - Educação & 26 & $7,20 \%$ \\
\hline 04 & UFMG - Educação & 17 & $4,70 \%$ \\
\hline 05 & UNICAMP - Educação & 15 & $4,15 \%$ \\
\hline 06 & $\begin{array}{l}\text { Fundação UFMS - } \\
\text { Educação }\end{array}$ & 10 & $2,78 \%$ \\
\hline 07 & UFSC - Educação & 10 & $2,78 \%$ \\
\hline 08 & UFMT - Educação & 09 & $2,49 \%$ \\
\hline 09 & Fundação UFS - Educação & 08 & $2,22 \%$ \\
\hline 10 & UERJ - Educação & 08 & $2,22 \%$ \\
\hline 11 & $\begin{array}{l}\text { PUC/SP - Educação: } \\
\text { Currículo }\end{array}$ & 08 & $2,22 \%$ \\
\hline 12 & $\begin{array}{l}\text { UNESP/Araraquara - } \\
\text { Educação escolar }\end{array}$ & 07 & $1,93 \%$ \\
\hline 13 & UFF - Educação & 07 & $1,93 \%$ \\
\hline 14 & $\begin{array}{l}\text { Fundação UFPI - } \\
\text { Educação }\end{array}$ & 06 & $1,67 \%$ \\
\hline 15 & UFU - Educação & 06 & $1,67 \%$ \\
\hline & Total & 215 & $59,55 \%$ \\
\hline
\end{tabular}

Fonte: Banco de Teses da Capes (1987/2007).

Cabe destacar que quinze programas foram responsáveis por 215 trabalhos, o que representa mais da metade da produção. Os outros 146 trabalhos foram defendidos em 69 diferentes programas de pós-graduação, variando entre cinco e um trabalho defendido.

No conjunto dos quinze programas que apresentaram maior incidência, localizamos todos na área da educação.

Outro dado importante é a quantidade de pesquisas realizadas pelos dois programas mais representativos: o programa Educação: História, Política, Sociedade, da PUC/SP, e o programa Educação, da USP. Juntos, eles somaram 78 tra-

4- Nesse caso, o percentual estabelecido leva em conta o conjunto dos resumos analisados, ou seja, 361 . balhos, o que aponta 21,59\% do total e indica que um número expressivo de trabalhos foi realizado em apenas duas instituições. A esse respeito, cabe também destacar a produção da UFPR (programa Educação), que aparece em terceiro lugar no quadro geral, apresentando 26 produções, o que é significativo quando comparado com o número demonstrado pelas duas primeiras instituições.

De algum modo, esses dados ajudam-nos a entender a distribuição dos 361 trabalhos entre as diferentes regiões do Brasil, conforme nos revela o gráfico a seguir:

Gráfico 2 - Distribuição da produção de teses e dissertações por região do país

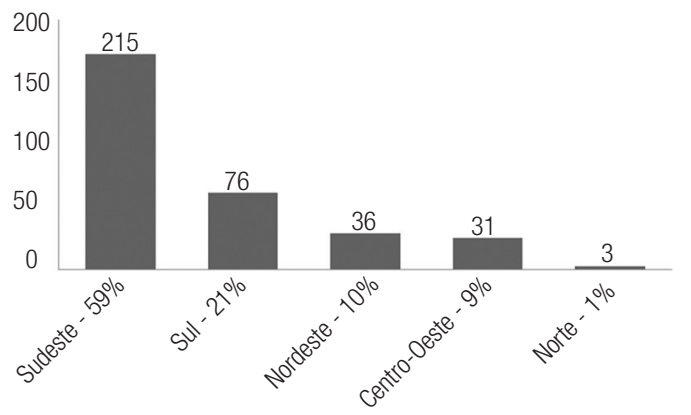

Fonte: Banco de Teses da Capes (1987/2007).

Podemos verificar que quase $60 \%$ dos trabalhos estão localizados na região Sudeste; em segundo lugar, aparece a região Sul, com um pouco mais de que $20 \%$. Isso significa que $80 \%$ da produção encontra-se no eixo Sul-Sudeste.

Sem dúvida, essa disparidade tem relação com a própria conformação da pós-graduação no país, como já apontado por Marin, Bueno e Sampaio (2005). Segundo os autores, o nível de desenvolvimento econômico dessas regiões e a longevidade de tais programas podem ser considerados como fatores explicativos dessa situação.

Apesar da forte concentração demonstrada na região Sudeste, não se pode deixar de registrar que houve a localização de produção em todas as regiões do país; consequentemente, essa evidência vai repercutir na localização dos orientadores das pesquisas.

Inicialmente, os dados indicam que 253 pesquisadores orientaram os 361 trabalhos, o 
que revela um número significativo de dispersão. No entanto, se somarmos os indivíduos que orientaram três ou mais pesquisas, temos 23 pesquisadores que orientaram entre dezoito e três estudos, o que totaliza 101 trabalhos e representa $27,97 \%$ do total. Vejamos a tabela:

Tabela 6 - Orientadores e número de trabalhos sobre cultura escolar

\begin{tabular}{|c|c|c|}
\hline & Orientador (a) & $\mathrm{N}^{\circ}$ \\
\hline 1 & Alda Junqueira Marin - PUC/SP - Educação: HPS ${ }^{5}$ & 18 \\
\hline 2 & Nicanor Palhares Sá - UFMT - Educação & 7 \\
\hline 3 & Eurize Caldas Pessanha - UFMS - Educação & 5 \\
\hline 4 & Luciana Maria Giovanni - PUC/SP - Educação: HPS & 5 \\
\hline 5 & Marcus Levy Albino Bencostta - UFPR - Educação & 5 \\
\hline 6 & Maria Auxiliadora M. dos Santos Schmidt - UFPR -Educação & 5 \\
\hline 7 & Maria das Mercês Ferreira Sampaio - PUC/SP - Educação: HPS & 5 \\
\hline 8 & Jorge Carvalho do Nascimento - UFSE - Educação & 4 \\
\hline 9 & Luciano Mendes de Faria Filho - UFMG - Educação & 4 \\
\hline 10 & $\begin{array}{l}\text { Marta M. C. Carvalho - PUC/SP - Educação: HPS (1) e } \\
\text { USP - Educação (3) }\end{array}$ & 4 \\
\hline 11 & Belmira Amélia de Barros Oliveira Bueno - USP - Educação & 3 \\
\hline 12 & Diana Gonçalves Schmidt - USP - Educação & 3 \\
\hline 13 & José Geraldo Silveira Bueno - PUC/SP - Educação: HPS & 3 \\
\hline 14 & Leilah Santiago Bufrem - UFPR - Educação & 3 \\
\hline 15 & Luiz Antonio Gomes Senna - UERJ - Educação & 3 \\
\hline 16 & $\begin{array}{l}\text { Maria Aparecida J. Veiga Gaeta - Centro Universitário } \\
\text { Moura Lacerda - Educação }\end{array}$ & 3 \\
\hline 17 & Maria Cristina Menezes - UNICAMP - Educação & 3 \\
\hline 18 & Maria do Amparo Borges Ferro - UFPI - Educação & 3 \\
\hline 19 & Maria Rita de Almeida Toledo - PUC/SP - Educação: HPS & 3 \\
\hline 20 & Neuza Bertoni Pinto - PUC/PR - Educação & 3 \\
\hline 21 & Tânia Maria Figueiredo Braga Garcia - UFPR - Educação & 3 \\
\hline 22 & $\begin{array}{l}\text { Vicente Molina Neto - UFRGS - Ciências do Movimento } \\
\text { Humano }\end{array}$ & 3 \\
\hline 23 & $\begin{array}{l}\text { Wagner Rodrigues Valente - PUC/SP - Educação } \\
\text { Matemática }\end{array}$ & 3 \\
\hline & Total & 101 \\
\hline
\end{tabular}

Esse reagrupamento confirma mais uma vez a concentração das pesquisas no eixo SulSudeste. Mas, para além da tabela, se considerarmos os orientadores de dois trabalhos, temos trinta pesquisadores, totalizando mais de sessenta trabalhos. Desta forma, restam outros 200 pesquisadores que orientaram apenas um trabalho, o que volta a indicar uma tendência de dispersão nas orientações das pesquisas.

No entanto, o cruzamento dos dados relativos aos orientadores e às suas instituições de origem mostra a concentração em dois programas de pós-graduação: Educação: História, Política, Sociedade, da PUC/SP, e Educação, da UFPR. Dos 41 trabalhos defendidos no primeiro programa, 34 estão concentrados em cinco orientadores; dos 26 trabalhos defendidos no programa da UFPR, dezesseis foram orientados por apenas quatro diferentes pesquisadores. Observemos as tabelas:

Tabela 7 - Orientadores do programa de pós-graduação da PUC/SP (Educação: História, Política, Sociedade) e número de trabalhos orientados

\begin{tabular}{c|lc} 
& Orientador(a) - PUC/SP - Educação: HPS & No \\
\hline 1 & Alda Junqueira Marin & 18 \\
\hline 2 & Luciana Maria Giovanni & 5 \\
\hline 3 & Maria das Mercês Ferreira Sampaio & 5 \\
\hline 4 & José Geraldo Silveira Bueno & 3 \\
\hline 5 & Maria Rita de Almeida Toledo & 3 \\
\hline & Total & 34 \\
\hline
\end{tabular}

Fonte: Banco de Teses da Capes (1987/2007).

Tabela 8 - Orientadores do programa de pós-graduação da UFPR (Educação) e número de trabalhos orientados

\begin{tabular}{c|l|c} 
& Orientador (a) - UFPR: Educação & No \\
\hline 1 & Marcus Levy Albino Bencostta & 5 \\
\hline 2 & Maria Auxiliadora M. dos Santos Schmidt & 5 \\
\hline 3 & Leilah Santiago Bufrem & 3 \\
\hline 4 & Tânia Maria Figueiredo Braga Garcia & 3 \\
\hline & Total & 16 \\
\hline
\end{tabular}

Fonte: Banco de Teses da Capes (1987/2007). 
Vale ressaltar que ora a concentração pode ser esforço de um programa de pós-graduação, ora de um professor, conforme ocorre no programa de Educação da UFMT: dos nove trabalhos defendidos nessa instituição, quase a totalidade (sete trabalhos) foi orientada por apenas um pesquisador - Nicanor Palhares Sá.

Ainda sobre esse aspecto, a situação do programa de Educação da USP chamou-nos a atenção. Apesar de figurar como a segunda instituição com o maior número de trabalhos defendidos (37), apenas três pesquisadores orientaram três trabalhos cada um, totalizando nove trabalhos; outros quatro pesquisadores orientaram dois trabalhos e mais vinte pesquisadores orientaram apenas um trabalho, o que demonstra que 27 diferentes pesquisadores foram responsáveis pelas orientações dos 37 trabalhos defendidos. Isso indica uma forte dispersão entre os orientadores e, por outro lado, demonstra a amplitude do programa de pesquisa sugerido por Azanha (1990-1991) e a forma como a instituição o desenvolveu por meio de diferentes projetos, a maioria deles no âmbito da história da educação (VIDAL, 2005).

Em outra tentativa de examinar o modo como a noção de cultura escolar vem sendo apropriada pelos pesquisadores brasileiros, procedemos à análise em torno dos autores referenciados na elaboração dessas teses e dissertações. Inicialmente, vale destacar que, dos 361 trabalhos, 129 informaram os autores de referência, ou seja, 35,73\% do total, o que pode ser considerada uma amostra significativa para a análise aqui pretendida.

Em muitos desses trabalhos, surgem autores que tratam especificamente da cultura escolar, mas também outros autores. Nesse sentido, houve pesquisas que informaram apenas um autor e outras que disseram basear-se em mais autores (o que variou de dois a quinze diferentes autores em um mesmo trabalho), totalizando o número de 3.915 diferentes autores. Diante dessa variação de universo, optamos por analisar apenas os autores que foram citados em dez ou mais trabalhos, a fim de examinar possíveis tendências, o que pode ser visualizado na tabela que segue:

Tabela 9-Autores mais referenciados nas teses e dissertações

\begin{tabular}{l:l:c} 
& Autores & Frequência \\
\hline 1 & Dominique Julia & 26 \\
\hline 2 & Antonio Viñao Frago & 21 \\
\hline 3 & Roger Chartier & 20 \\
\hline 4 & Pierre Bourdieu & 18 \\
\hline 5 & Michel de Certeau & 18 \\
\hline 6 & José Gimeno Sacristán & 17 \\
\hline 7 & Mikhail Bakhtin & 13 \\
\hline 8 & Pérez Gómez & 12 \\
\hline 9 & André Chervel & 11 \\
\hline 10 & Michel Foucault & 10 \\
\hline Fon & Band & \\
\hline
\end{tabular}

Fonte: Banco de Teses da Capes (1987/2007).

É compreensivel e inclusive esperado que, em se tratando de pesquisas que utilizam a noção de cultura escolar, cultura da escola ou cultura na escola, os autores mais referenciados sejam aqueles que sistematicamente se debruçam sobre seu estudo, tendo até mesmo criado e difundido tal noção, como é o caso dos historiadores Julia, Viñao Frago e Chartier, conforme destacado por Faria Filho et al. (2004) e Gonçalves e Faria Filho (2005). No entanto, no montante dos trabalhos aqui analisados, a utilização desses autores não ficou restrita apenas aos estudos históricos, mas esteve presente também em estudos contemporâneos, o que poderia revelar-nos que suas análises transitam por produções em diferentes perspectivas e recortes cronológicos.

Vale destacar que Jean-Claude Forquin foi mencionado por seis trabalhos, ficando na $13^{a}$ posição de nossa lista. Tal fato chamou nossa atenção, pois, ao lado dos outros autores, ele também foi mencionado como importante para a divulgação da noção no país (VIDAL, 2005; FARIA FILHO et al., 2004; GONÇALVES; FARIA FILHO, 2005).

Outro fator em comum é a frequência dos autores ao longo dos anos. Os trabalhos que 
informaram utilizar tais autores foram quase todos defendidos após o ano 2000, com predo- minância nos trabalhos defendidos após 2004, como mostra a tabela a seguir:

Tabela 10 - Frequência dos autores por ano

\begin{tabular}{|c|c|c|c|c|c|c|c|c|c|c|c|}
\hline Autores/ano & $\begin{array}{l}1987 / \\
1997\end{array}$ & 1998 & $\begin{array}{c}1999 / \\
2000\end{array}$ & 2001 & 2002 & 2003 & 2004 & 2005 & 2006 & 2007 & Total \\
\hline Dominique Julia & 0 & 0 & 0 & 1 & 0 & 1 & 7 & 3 & 6 & 8 & 26 \\
\hline Antonio Viñao Frago & 0 & 0 & 0 & 0 & 2 & 2 & 4 & 2 & 3 & 8 & 21 \\
\hline Roger Chartier & 0 & 0 & 0 & 0 & 0 & 1 & 3 & 3 & 3 & 10 & 20 \\
\hline Pierre Bourdieu & 0 & 0 & 0 & 1 & 0 & 4 & 3 & 3 & 2 & 5 & 18 \\
\hline Michel de Certeau & 0 & 0 & 0 & 0 & 0 & 1 & 3 & 5 & 4 & 5 & 18 \\
\hline José Gimeno Sacristán & 0 & 0 & 0 & 1 & 1 & 0 & 3 & 4 & 5 & 3 & 17 \\
\hline Mikhail Bakhtin & 0 & 1 & 0 & 0 & 0 & 2 & 0 & 3 & 4 & 3 & 13 \\
\hline Pérez Gómez & 0 & 0 & 0 & 1 & 0 & 0 & 2 & 2 & 4 & 3 & 12 \\
\hline André Chervel & 0 & 0 & 0 & 0 & 0 & 1 & 0 & 0 & 4 & 6 & 11 \\
\hline Michel Foucault & 0 & 0 & 0 & 1 & 0 & 0 & 2 & 2 & 2 & 3 & 10 \\
\hline
\end{tabular}

Fonte: Banco de Teses da Capes (1987/2007).

Poucos desses trabalhos citaram apenas um autor, sendo frequente a referência conjunta a dois ou mais autores. Nesse sentido, as duplas mais comuns foram: Julia e Viñao Frago; Chartier e Certeau; Gimeno Sacristán e Pérez Gómez.

Outro aspecto analisado refere-se aos níveis e modalidades de ensino pesquisados. Do total dos 361 resumos, esse aspecto foi explicitado em 221 (61,22\%). Desse conjunto, separamos os que realizaram estudos contemporâneos (151, ou seja, 68,33\%) daqueles que realizaram estudos do tipo histórico (70, ou seja, 31,67\%).

Tendo em vista os limites deste artigo, no que se refere aos níveis e modalidades de ensino pesquisados, optamos por apresentar apenas os dados relativos aos 151 resumos referentes ao período contemporâneo. Para essa opção, consideramos o fato de já existirem estudos dirigidos à análise da incorporação da noção de cultura escolar no campo histórico (FARIA FILHO et al., 2004; SOUZA; FARIA FILHO, 2006; GONÇALVES; FARIA FILHO, 2005; entre outros), bem como nosso propósito de maior aproximação aos campos de estudos contemporâneos, com os quais possuímos maior convergência investigativa.
Nesse sentido, a distribuição dos trabalhos entre os níveis ou modalidades de ensino organiza-se da seguinte forma:

a) ensino fundamental: 93 resumos, ou seja, 61,58\% (do total de 151);

b) ensino médio: 27 resumos, ou seja, 17,88\%;

c) ensino superior: 14 resumos, ou seja, 9,27\%;

d) educação infantil: 11 resumos, ou seja, 7,28\%.

Além desses níveis de ensino, apareceram em menor quantidade trabalhos relacionados a educação indígena, educação especial, entre outros.

Ao observar o conjunto dos dados, verificamos um vasto volume de estudos relativos ao ensino fundamental, fato que demonstra a intensa preocupação acadêmica com esse nível de ensino. Nesse sentido, decidimos proceder a um exame mais rigoroso sobre essas informações, o que redundou em uma espécie de desdobramento analítico que indica a prevalência de certas temáticas investigativas, conforme veremos a seguir. Sem dúvida, esse mesmo exercício poderia ser realizado com os demais níveis e modalidades, mas, considerando os limites de tempo e espaço desta publicação, não realizaremos tal empreito. 
Assim, ao tentar compreender melhor a produção relativa ao ensino fundamental, chamou-nos a atenção a frequência de trabalhos que analisaram ciclo, além de uma quantidade um pouco mais equilibrada de pesquisas que trataram dos anos iniciais e finais do ensino fundamental, conforme podemos visualizar na tabela 11:

Tabela 11 - Distribuição dos estudos relativos ao ensino fundamental por série, ano, ciclo etc.

\begin{tabular}{|c|c|c|c|}
\hline \multicolumn{2}{|l|}{ Ensino fundamental } & $\mathrm{N}^{0}$ & $N^{0}$ \\
\hline \multicolumn{2}{|c|}{ EF6 sem especificar série/ano } & 30 & 30 \\
\hline \multirow{4}{*}{$\begin{array}{l}\text { EF especificando séries/ } \\
\text { anos iniciais }\end{array}$} & $\mathrm{EF}-\mathrm{Sl}^{7}$ & 10 & \multirow{4}{*}{18} \\
\hline & $\begin{array}{l}\text { EF - SI - 1ª série/ } \\
\text { alfabetizacão }\end{array}$ & 5 & \\
\hline & $\mathrm{EF}-\mathrm{SI}-3^{\mathrm{a}}$ série & 1 & \\
\hline & $\mathrm{EF}-\mathrm{SI}-4^{\mathrm{a}}$ série & 2 & \\
\hline \multirow{4}{*}{$\begin{array}{l}\text { EF especificando séries/ } \\
\text { anos finais }\end{array}$} & $\mathrm{EF}-\mathrm{SF}^{8}$ & 11 & \multirow{4}{*}{14} \\
\hline & $\mathrm{EF}-\mathrm{SF}$ - $5^{\mathrm{a}}$ série & 1 & \\
\hline & $\begin{array}{l}\mathrm{EF}-\mathrm{SF}-5^{\mathrm{a}} \text { e } 6^{\mathrm{a}} \\
\text { séries }\end{array}$ & 1 & \\
\hline & EF - SF - 8a série & 1 & \\
\hline \multicolumn{2}{|c|}{ Estudos específicos sobre ciclos } & 31 & 31 \\
\hline \multicolumn{2}{|c|}{ Total de resumos do ensino fundamental } & 93 & 93 \\
\hline
\end{tabular}

Fonte: Banco de Teses da Capes (1987/2007).

A grande quantidade de estudos sobre ciclos faz-nos pensar que, quando se estuda a escola com esse tipo de organização de ensino, a cultura escolar passa a ser uma condição importante para sua compreensão. Esse destaque aos estudos voltados para a organização escolar por ciclos também é mencionado por Rosa e Serrão (2009), que se debruçam sobre as comunicações apresentadas nas reuniões da ANPEd entre 2000 e 2005, no GT 13 (ensino fundamental). Segundo as autoras, na análise dos 88 artigos delimitados pelo estudo, houve uma crescente preocupação em relação ao fracasso escolar e o ensino por ciclos foi o tema mais abordado durante o período analisado. Vale apontar, ainda, que a categoria tempo vem sendo destacada como um elemento importante na constituição

\footnotetext{
6- A sigla EF corresponde ao ensino fundamental.

7- A sigla SI corresponde às séries iniciais.

8- A sigla SF corresponde às séries finais.
}

da cultura escolar (VIÑAO FRAGO, 1995, 1998). Isso parece indicar que há uma aproximação de tais estudos com o corpo conceitual dessa tradição, ao se apropriarem dessa noção na análise de políticas que pretendem alterar o tempo da organização escolar.

Porém, interessadas ainda por detalhar a relação entre a utilização do termo cultura escolar e o estudo de aspectos específicos do ensino fundamental, compreendemos que uma pista importante poderia ser localizada nas palavras-chave apresentadas nos resumos. Nesse sentido, foi possível verificar que alguns estudos não as indicavam, alguns apresentavam uma ou duas, e a maioria mencionava três ou mais palavras-chave. Sendo assim, foi analisado um universo de 278 palavras-chave de resumos que declaravam estudar o ensino fundamental.

Após a leitura da listagem das palavras, optou-se por agrupá-las em temáticas e nomeá-las. Assim, quando foram encontradas, por exemplo, termos como formação de professores, formação docente, formação continuada, professores etc., reunimos tais palavras em torno da temática formação docente. Sobre essa forma de ordenação cabe um destaque. Sabe-se que toda classificação humana é social (DURKHEIM; MAUSS, 2005) e não natural ou óbvia, contendo, portanto, formas de exercício de poder. Assim, um agrupamento como o mencionado parece não apresentar problemas aparentes, mas como agrupar palavras tão interdisciplinares quanto corpo social, concepções pedagógicas, violência escolar? Nesses casos, algumas escolhas e decisões tiveram de ser tomadas e, nas situações em que não houve consenso, nem possibilidade de agrupamento/ reagrupamento, tais palavras foram registradas como outras, totalizando 32 palavras nessa categoria.

A tabela 12 aponta que a $1^{\text {a }}$ e a $3^{a}$ temáticas mais tratadas são escola e cultura escolar, o que não revela surpresa, uma vez que os resumos versavam justamente sobre isso. Mas nos chama atenção a quantidade de palavras que remetem ao campo de formação de professores 
no âmbito dos estudos sobre ensino fundamental e cultura escolar. Esse fato poderia indicar que tais estudos foram motivados por problemas recorrentes na formação de professores, frequentemente apontados por diversos pesquisadores da área. Por outro lado, a noção de cultura escolar pode ter-se apresentado como uma nova categoria interpretativa para pensar tais problemas.
No entanto, apenas uma análise mais detalhada do conteúdo desses trabalhos poderia confirmar tais hipóteses. De todo modo, vale ressaltar que a preferência pela temática dos professores também foi constatada por Carvalho (2002) em sua análise da produção dos projetos de pesquisa vinculados aos programas de pós-graduação no Brasil, entre 1996 a 2000.

Tabela 12 - Ensino fundamental e incidência das palavras-chave

\begin{tabular}{|c|c|}
\hline Palavras-chave & Frequência \\
\hline $\begin{array}{l}\text { Escola, escola pública, escolaridade, escolarização, ensino fundamental, diferentes tipos de escola (ex.: escola do } \\
\text { campo, escola rural) etc. }\end{array}$ & 33 \\
\hline Formação de professores, formação continuada, docência, identidade profissional docente etc. & 31 \\
\hline Cultura escolar, culturas escolares, cultura da escola etc. & 25 \\
\hline Gestão, gestão democrática, gestão escolar, política educacional, reforma educacional, democratização etc. & 25 \\
\hline Ciclos, progressão continuada etc. & 21 \\
\hline Currículo, interdisciplinaridade, temas transversais, livro didático etc. & 19 \\
\hline Metodologias de ensino, ensino-aprendizagem, ensino de... (história, matemática, educação física) etc. & 16 \\
\hline Inclusão, exclusão etc. & 13 \\
\hline Avaliação, Projeto Político Pedagógico, papel do pedagogo, planejamento educacional etc. & 11 \\
\hline Cultura, estudos culturais etc. & 10 \\
\hline Aluno, criança, jovem, infância etc. & 8 \\
\hline Inovação (inovação, mudança etc.) e tecnologia (computador, internet, televisão etc.). & 10 \\
\hline Violência, indisciplina, controle etc. & 8 \\
\hline Diversidade, multiculturalidade, educação intercultural etc. & 8 \\
\hline Alfabetização e leitura. & 8 \\
\hline Total de palavras analisadas & 246 \\
\hline Palavras não agrupadas (ex.: negociação, rituais, apropriação etc.) & 32 \\
\hline Total geral de palavras & 278 \\
\hline
\end{tabular}

Fonte: Banco de Teses da Capes (1987/2007).

Já o expressivo número de pesquisas sobre gestão escolar e politica educacional, assim como sobre estudos curriculares e organização do ensino por ciclos, indica serem estas temáticas recorrentes quando se fala em ensino fundamental. A relação com as discussões da cultura escolar pode indicar que essa noção torna-se profícua para tais análises.
Sobre as palavras menos citadas, verifica-se que, quando o interesse é a discussão do sujeito escolar como uma ampla categoria (por exemplo, o aluno, a criança, o jovem) e não como uma categoria específica (por exemplo, jovem em situação de rua, ou aluno surdo, estes incluídos na categoria inclusão, exclusão), a 
primeira ainda não aparece como uma temática significativa em termos numéricos.

No entanto, se somarmos temáticas como diversidade e multiculturalidade (oito resumos), exclusão (treze resumos) e violência (oito resumos), juntas, elas se aproximariam dos primeiros lugares em termos de temáticas mais pesquisadas. 0 estudo de alunos específicos (aqueles que sofrem violência, preconceito, aqueles que permanecem em situação de fracasso, os incluídos de forma inadequada etc.), portanto, parece indicar que situações de exclusão ainda são, infelizmente, muito recorrentes nas escolas brasileiras. Os estudos de questões raciais e de gênero parecem apontar para a mesma direção. Nesse sentido, estariam esses dados ilustrando as tensões vividas na escola quando esta universaliza o ensino fundamental, elimina a reprovação, desenvolve políticas de inclusão e quando o campo curricular e as políticas afirmativas passam a discutir mais detidamente questões sobre a diversidade?

Outra temática que numericamente teve índices relativamente menores em comparação com outras foi a de alfabetização e leitura. Talvez isso ocorra porque esse tipo de pesquisa não precisa necessariamente estabelecer relação com estudos de cultura escolar, podendo aparecer de maneira mais ampliada nas teses e dissertações do campo da educação e da alfabetização. Por outro lado, vários estudiosos da cultura escolar (HÉBRARD, 1990; VIÑAO FRAGO, 1993) convergem suas atenções para o âmbito da leitura e da escrita, algo que parece não impactar a produção discente dos programas de pós-graduação no Brasil.

Sobre os silêncios e as ausências em termos de pesquisa, um aspecto que nos chamou a atenção foi a inexistência de palavras-chave relacionadas à família e à comunidade. Tal fato, indubitavelmente, faz-nos pensar que as discussões proporcionadas pela cultura escolar podem ter provocado menos o olhar para a relação da escola com seu entorno/contexto e mais para aquilo que ocorre no interior dela mesma. Com certeza, essa seria uma pista interessante para continuarmos pesquisando. Ou seja, será que isso pode ser indício de uma interpretação restritiva da própria noção?

Nesse contexto, vale lembrar que diversos autores que pesquisaram sobre a cultura escolar conceberam uma relação necessária entre esta e os elementos mais amplos do contexto social. A título de exemplo, poderíamos mencionar a pesquisa de Viñao Frago (1998) sobre a distribuição do tempo e do trabalho no ensino primário na Espanha de 1838 a 1936. 0 autor, além de confrontar três pontos de vista importantes sobre a cultura escolar daquele período - quais sejam, o teórico (as propostas de pedagogos, inspetores e professores), o legal (as normas que regulam esta questão) e o escolar (o que acontecia nas escolas) -, chama a atenção para um quarto aspecto de análise: a realidade social externa à escola. Há ainda o estudo de Souza (1998), que, ao examinar a implantação da escola primária graduada no Estado de São Paulo, não perde de vista nem a relação da escola com o bairro e a cidade, nem com o ideário republicano propagado na época.

Nesse sentido, acreditamos que, se o conceito de cultura escolar não for operado de sorte a abranger esse contexto social mais amplo, ele poderá perder parte de sua potencialidade explicativa e de sua criticidade, conforme já apontam Faria Filho et al. (2004).

\section{Alguns destaques e desafios}

Após essa caracterização inicial da produção de pesquisas sobre cultura escolar por meio da análise dos resumos de dissertações/teses defendidas nos programas de pós-graduação brasileiros e catalogadas no Banco de Teses da Capes, alguns aspectos merecem destaque.

0 material aqui analisado, referente a um período de vinte anos de pesquisa, mostra uma tendência de expansão nos estudos sobre cultura escolar ao longo dos anos. No entanto, esse crescimento evidencia uma concentração desses estudos no eixo Sul-Sudeste, o que 
corrobora a influência que a tradição histórica desses programas de pós-graduação tem sobre o restante da produção.

A partir desta análise, foi possível perceber que as diferenciações entre cultura escolar, cultura da escola e cultura na escola não foram consideradas pela ampla maioria dos pesquisadores aqui analisados. A preferência, tanto de estudos históricos quanto de estudos contemporâneos, foi pelo emprego de cultura escolar, o que pode demonstrar uma utilização mais abrangente do termo.

Vale ressaltar que, de modo geral, foi constatada uma dispersão dos orientadores de tais pesquisas no Brasil, havendo esforço de concentração em poucos programas (PUC/SP Educação: HPS e UFPR - Educação) e/ou em alguns orientadores. Essa dispersão pode indicar que os pesquisadores que se vêm debruçando sobre os estudos da cultura escolar estão espalhados pelo território nacional, ou então que o termo vem sendo usado de forma genérica pela maioria dos autores, sem se aterem necessariamente à tradição investigativa aqui apontada. Isso deverá ser analisado futuramente a partir de uma leitura mais pormenorizada das teses e dissertações, algo que ainda não foi possível tendo em vista os objetivos iniciais deste levantamento.

Na sequência desta publicação, também procuraremos examinar se os resultados de tal produção conseguem estabelecer reflexões entre os meandros do interior da escola e aspectos mais amplos da vida social. Em outras palavras, se as teses e dissertações aqui arroladas realmente revelam elementos significativos para entender a escola e seus impactos sobre a cultura (ou vice-versa), proporcionando um repertório analítico capaz de confirmar a po- tencialidade explicativa que a tradição investigativa anuncia. A esse respeito, devemos levar em conta o alerta feito por Souza e Faria Filho (2006) ao mapearem a produção dos estudos sobre grupos escolares que tomaram a noção de cultura escolar como referência:

0 que temos observado é que a noção de cultura escolar tem sido empregada na maioria dos estudos muito mais como um recurso descritivo do que analítico. Nossa apropriação da noção de cultura escolar tem nos ajudado muito a perceber que elementos como conhecimentos, espaços, tempos, metodologias, materiais pedagógicos etc. constituem a cultura escolar, mas pouco temos avançado nas respostas às perguntas de como os sujeitos escolares produzem a cultura escolar e, no mesmo movimento, de como as culturas escolares produzem os sujeitos que dela fazem parte. (p. 39)

Ou seja, faz-se necessário avaliar se as pesquisas que utilizam a noção de cultura escolar vêm-se apropriando de tal noção de maneira crítica e densa ou utilizando-a somente como recurso descritivo. Só assim será possível verificar se esses estudos têm contribuído para a construção de um corpus analítico capaz de fomentar um mapeamento cultural da escola, conforme sugerido por Azanha (1990-1991).

Por fim, acreditamos que o estudo ora apresentado e seus desdobramentos poderão ser fecundos no próprio reconhecimento da produção que envolve a noção de cultura escolar, e que isso poderá fornecer contribuições significativas para a compreensão do funcionamento das escolas brasileiras. 


\section{Referências}

AZANHA, José Mário Pires. Cultura escolar brasileira: um programa de pesquisa. Revista da USP, São Paulo, n. 8, p. 37-40, 1990-1991.

CÂNDIDO, Antônio. A estrutura da escola. In: PEREIRA, Luiz; FORACCHI, Marialice M. (Orgs.). Educação e sociedade: leituras de sociologia da educação. 10. ed. São Paulo: Companhia Editora Nacional, 1979. p. 107-128.

CARVALHO, Marise Santos. Quem pesquisa ensino fundamental no Brasil de hoje? In: REUNIÃO ANUAL DA ANPED, 25., 2002, Caxambu. Anais... Rio de Janeiro: ANPEd, 2002.

CHERVEL, André. História das disciplinas escolares: reflexões sobre um campo de pesquisa. Teoria \& Educação, Porto Alegre, V. 2, p. 177-229, 1990.

DURKHEIM, Émile; MAUSS, Marcel. Contribuições para o estudo das representações coletivas. In: MAUSS, Marcel (Org.). Ensaios de sociologia. 2. ed. São Paulo: Perspectiva, 2005.

FARIA FILHO, Luciano Mendes de et al. A cultura escolar como categoria de análise e como campo de investigação na história da educação brasileira. Educação e Pesquisa, São Paulo, v. 30, n. 1, p. 139-159, jan./abr. 2004.

FORQUIN, Jean-Claude. Escola e cultura: as bases sociais e epistemológicas do conhecimento escolar. Porto Alegre: Artes Médicas, 1993.

GONÇALVES, Irlen Antônio; FARIA FILHO, Luciano Mendes de. História das culturas e das práticas escolares: perspectivas e desafios teórico-metodológicos. In: SOUZA, Rosa Fátima; VALDEMARIN, Vera Teresa (Orgs.). A cultura escolar em debate: questões conceituais, metodológicas e desafios para a pesquisa. Campinas: Autores Associados, 2005. p. 31-57.

HEBRARD, Jean. A escolarização dos saberes elementares na época moderna. Teoria \& Educação, Porto Alegre, v. 2, p. 65-109, 1990.

JULIA, Dominique. A cultura escolar como objeto histórico. Revista Brasileira de História da Educação, Campinas, n. 1, p. 9-43, 2001.

MAFRA, Leila de Alvarenga. A sociologia dos estabelecimentos escolares: passado e presente de um campo de pesquisa em reconstrução. In: ZAGO, Nadir et al. (Orgs.). Itinerários de pesquisa: perspectivas qualitativas em sociologia da educação. Rio de Janeiro: DP\&A, 2003. p. 109-136.

MARIN, Alda Junqueira; BUENO, José Geraldo Silveira; SAMPAIO, Maria das Mercês F. Escola como objeto de estudo nos trabalhos acadêmicos brasileiros: 1981/1998. Cadernos de Pesquisa, São Paulo, v. 35, n. 124, p. 171-199, jan./abr. 2005.

PÉREZ GÓMEZ, A. I. A cultura escolar na sociedade neoliberal. Tradução de Ernani Rosa. Porto Alegre: Artes Médicas, 2001.

ROSA, Solange Aparecida da; SERRÃO, Maria Isabel Batista. Escola e formação escolar: reflexões a partir da produção do grupo de trabalho Educação Fundamental da ANPEd (2000-2005). In: REUNIÃO ANUAL DA ANPED, 32., 2009, Caxambu. Anais... Rio de Janeiro: ANPEd, 2009.

SILVA, Tomaz Tadeu da. Documentos de identidade: uma introdução às teorias do currículo. 2. ed. Belo Horizonte: Autêntica, 1999.

SILVA, Fabiany de Cássia Tavares. Cultura escolar: quadro conceitual e possibilidades de pesquisa. Educar em revista, Curitiba, n. 28, p. 201-206, 2006.

SOUZA, Rosa Fátima de Souza. Templos de civilização: a implantação da escola primária graduada no estado de São Paulo (1890-1910). São Paulo: UNESP, 1998.

SOUZA, Rosa Fátima de; FARIA FILHO, Luciano Mendes de. A contribuição dos estudos sobre grupos escolares para a renovação da história do ensino primário no Brasil. In: VIDAL, Diana Gonçalves (Org.). Grupos escolares: cultura escolar primária e escolarização da infância no Brasil (1893-1971). Campinas: Mercado das letras, 2006. p. 21-56.

VIDAL, Diana Gonçalves. Cultura e prática escolares: uma reflexão sobre documentos e arquivos escolares. In: SOUZA, Rosa Fátima 
de; VALDEMARIN, Vera Teresa (Orgs.). A cultura escolar em debate: questões conceituais, metodológicas e desafios para a pesquisa. Campinas: Autores Associados, 2005. p. 03-30.

VIÑAO FRAGO, Antonio. Alfabetização na sociedade e na história: vozes, palavras e textos. Porto Alegre: Artes Médicas, 1993.

. Historia de la educación y historia cultural: posibilidades, problemas, cuestiones. Revista Brasileira de Educação, Rio de Janeiro, n. 0, p. 63-82, 1995.

. Por una história de la cultura escolar: enfoques, cuestiones, fuentes. In: FERNANDEZ, Celso Almuiña et al. Cultura y civilizaciones. III Congreso de la Asociación de Historia contemporánea. Valladolid: Secretariado de Publicaciones e Intercambio Cientifico, Universidade de Valladolid, 1998. p. 167-183.

Fracassan las reformas educativas? In: SOCIEDADE BRASILEIRA DE HISTÓRIA DA EDUCAÇÃO (Org.). Educação no Brasil. Campinas: Autores Associados, 2001. p. 21-52.

WALLER, Willard. The sociology of teaching. Tradução de Alda Junqueira Marin. New York: Russel \& Russel, 1961.

Recebido em: 02.08.2011

Aprovado em: 09.04.2012

Adriane Knoblauch é doutora em Educação pela Pontifícia Universidade Católica de São Paulo (PUCSP) e professora do Setor de Educação da Universidade Federal do Paraná (UFPR).

Ana Lúcia Silva Ratto é doutora em Educação pela Universidade Federal do Rio Grande do Sul (UFRGS) e professora do Setor de Educação da Universidade Federal do Paraná (UFPR). E-mail: ratto.ana@gmail.com.

Luciane Paiva Alves de Oliveira é doutora em Educação pela Pontifícia Universidade Católica de São Paulo (PUCSP) e professora do Setor de Educação da Universidade Federal do Paraná (UFPR). E-mail: luciane-paiva@uol.com.br.

Valéria Milena Rohrich Ferreira é doutora em Educação pela Pontifícia Universidade Católica de São Paulo (PUCSP) e professora do Setor de Educação da Universidade Federal do Paraná (UFPR). E-mail: vmilena@netpar.com.br. 